\title{
Diagnosis of an indistinct Leydig cell tumor by positron emission tomography-computed tomography
}

\author{
Jinkyoung Kong', Yoo Mee Park', Young Sik Choi' ${ }^{1}$, SiHyun Cho', Byung Seok Lee', Joo Hyun Park \\ Department of Obstetrics and Gynecology, ${ }^{1}$ Gangnam Severance Hospital, ${ }^{2}$ Severance Hospital, Yonsei University College of Medicine, Seoul, Korea
}

A 51-year-old perimenopausal female patient presented with hirsutism and voice thickening which was started approximately one and a half years ago. Her initial hormone assay revealed elevated plasma testosterone, 5a-dihydrotestosterone, and dehydroepiandrosterone (DHEA) levels and therefore androgen-secreting tumor was first suspected. However, the lesion was inconspicuous on transvaginal sonography, abdominal-pelvic computed tomography (CT) scan, and pelvic magnetic resonance (MRI) imaging. Consequently, ${ }^{18} \mathrm{~F}$-fluorodeoxyglucose (FDG) positron emission tomography-CT was performed, which localized the lesion as a focal FDG uptake within the right adnexa. Total laparoscopic hysterectomy with bilateral salpingo-oophorectomy was performed, and although visible gross mass lesions were not observed intraoperatively, pure Leydig cell tumor was pathologically confirmed within the right ovary. Plasma testosterone, 5a-dihydrotestosterone, and DHEA levels were normalized postoperatively. Clinical signs of virilization were also significantly resolved after 3-months of follow-up.

Keywords: Sertoli-Leydig cell tumor; PET-CT; Diagnosis

\section{Introduction}

Ovarian Sertoli-Leydig cell tumor (SLCT) is a rare ovarian neoplasm belonging to the subgroup of sex cord-stromal tumors, with a worldwide incidence rate of $<0.5 \%$ [1], which can manifest as either benign or malignant. Although approximately $75 \%$ of cases occur in female before the age of 40 years, the disease can still affect females of all ages. As the tumor comprises a testicular structure, it often results in overproduction of androgens; therefore, overt androgenic effects occur in approximately $30 \%$ of patients; clinical symptoms, such as hirsutism, thickening of voice, and male patterns of fat distribution may also occur [2]. SLCT may be suspected if the clinical manifestation is virilization or the plasma testosterone level is $>6.5 \mathrm{nmol} / \mathrm{L}$ [1]. Mostly, conventional radiologic imaging studies can localize SLCT when the size of the tumor mass is significant. However, some tumors may be too small to localize and make an appropriate differential diagnosis before surgical exploration. When conventional imaging modalities commonly performed for ovarian tumors fail, the profiles of adjunctive imaging studies are not well described for SLCT. Here, we report a patient with clinical symptoms and signs of SCLT; however, findings of abdominal-pelvic computed tomography (CT) and pelvic magnetic resonance imaging (MRI) were inconclusive, whereas positron emission tomography-CT (PET-CT) findings aided in precisely localizing the tumor.

\section{Case report}

A 51-year-old female patient presented with hirsutism on her face, chest, abdomen, and legs together with facial swell-

Received: 2018.07.19. Revised: 2018.09.24. Accepted: 2018.10.24 Corresponding author: Joo Hyun Park

Department of Obstetrics and Gynecology, Gangnam Severance Hospital, Yonsei University College of Medicine, 211 Eonju-ro, Gangnam-gu, Seoul 06273, Korea

E-mail: beanpearl@yuhs.ac

https://orcid.org/0000-0001-6388-5975

Articles published in Obstet Gynecol Sci are open-access, distributed under the terms of the Creative Commons Attribution Non-Commercial License (http://creativecommons. org/licenses/by-nc/3.0/) which permits unrestricted non-commercial use, distribution, and reproduction in any medium, provided the original work is properly cited.

Copyright (๑ 2019 Korean Society of Obstetrics and Gynecology 


\section{Obstetrics \& Gynecology Science}

Jinkyoung Kong, et al. Sertoli-Leydig cell tumor with PET-CT

ing and deepening of voice, which started approximately 18 months ago. The patient had an obstetric history of gravida 2, para 2, and had irregular menstrual bleeding. Her last menstrual period was about 6 weeks ago. She was under medication for hypertension and asthma, and had received bilateral thyroidectomy 4 years ago due to thyroid cancer. Physical examination revealed hirsutism involving the chin, philtrum, chest, abdomen, and extremities (Fig. 1A). Signs of moon face and central obesity were also manifested, with a body mass index (BMI) of $37.8 \mathrm{~kg} / \mathrm{m}^{2}$. No palpable abdominal or pelvic lesions were observed.

The patient was on a fluticasone furoate-containing inhaler for 20 years due to asthma and was first admitted to the endocrinology department to rule out Cushing's syndrome. However, the result of the overnight dexamethasone suppression test was negative. The initial laboratory investigations revealed normal complete blood count and normal hepatic and renal function. Tumor markers, including alpha- fetoprotein, cancer antigen (CA) 125, and CA 19-9, were not elevated. The concomitant hormonal test results were as follows: follicle-stimulating hormone (FSH), $9.3 \mathrm{mlU} / \mathrm{mL}$; luteinizing hormone (LH), $5.2 \mathrm{mlU} / \mathrm{mL}$; estradiol (E2), $48.5 \mathrm{pg} /$ $\mathrm{mL}$; cortisol, $10.4 \mathrm{mcg} / \mathrm{dL}$; total testosterone, $13.52 \mathrm{nmol} / \mathrm{L}$; free testosterone, 44.5 ; $5 a$-dihydrotestosterone, $0.54 \mathrm{ng} / \mathrm{mL}$; and dehydroepiandrosterone (DHEA), $71.8 \mathrm{mcg} / \mathrm{dL}$ (Table 1). With the highest likelihood of hormone-producing tumor as the differential diagnosis, abdominal-pelvis $C T$ was performed, but no remarkable findings were noted (Fig. 1B).

The patient was then referred to our reproductive endocrinology division for further evaluation, where she underwent transvaginal ultrasonography. The examination showed that the volume of the left ovary was $4.9 \mathrm{~cm}^{3}$ and of the right ovary was $9.7 \mathrm{~cm}^{3}$, with neither ovary showing any abnormal echogenicity other than a slight discrepancy in size (Fig. 1C). Identifiable lesions were not detected on pelvic MRI (Fig. 1D). A ${ }^{18}$ F-fluorodeoxyglucose (FDG) PET-CT scan was then per-
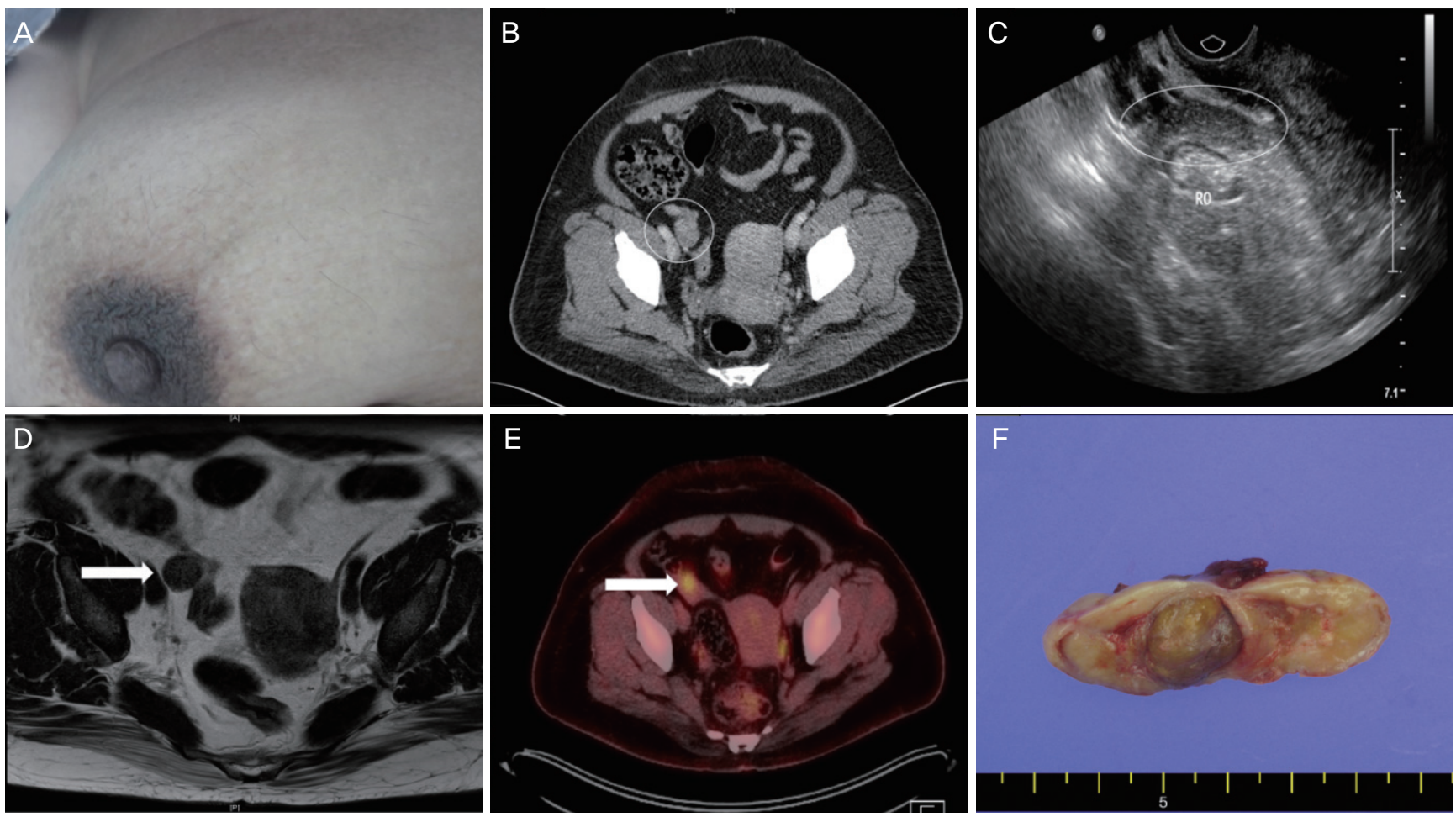

Fig. 1. (A) Truncal hirsutism: male pattern hair distribution on the patient's chest. (B) Lopromide contrast-enhanced abdominopelvic CT: nonspecific findings of the right ovary (white circle). (C) Transvaginal ultrasonography: no abnormal echogenicity in the patient's right ovary (white ellipse) and other pelvic structures. (D) T2-weighted MRI: ovoid-shaped homogeneous right ovary, and nonspecific findings of the right ovary (arrow). (E) ${ }^{18}$ F-FDG PET-CT: small focal FDG uptake in the right adnexa (arrow). (F) Macroscopic features of the pure Leydig cell tumor: yellow solid mass of $1.5 \mathrm{~cm}$ in size. CT, computed tomography; MRI, magnetic resonance imaging, FDG, fluorodeoxyglucose; PET-CT, positron emission tomography computed tomography. 


\title{
Obstetrics \& Gynecology Science
}

\author{
Vol. 62, No. 3, 2019
}

formed, revealing $0.7 \mathrm{~cm}$ focal FDG uptake within the right adnexa, with no abnormal uptake in other pelvic or distant organs (Fig. 1E).

Upon laparoscopic inspection of the abdominal cavity, the right ovary did not show any gross abnormalities on the cortical surface, and no other additional visible anomalies, such as nodules or ascites, were observed. After initially performing right salpingo-oophorectomy, the specimen was sent out for frozen section pathologic analysis, and was identified as pure Leydig cell tumor. Since the patient had no desire to preserve fertility, additional total laparoscopic hysterectomy with left salpingo-oophorectomy was performed. Grossly, the right ovary weighed $8.6 \mathrm{gm}$, and serial sections of the ovary revealed a yellow solid mass measuring approximately $1.5 \mathrm{~cm}$ (Fig. 1F). Microscopically, no capsular involvement was noted. On immunohistochemical staining, the tumor was positive for inhibin-a, calretinin, androgen, and Melan-A, with Ki-67 positivity of $1 \%$. The final pathology report concluded that the right ovarian mass was pure Leydig cell tumor.

The first assay of postoperative hormone levels, measured 3 weeks postoperatively, was as follows: testosterone of $<0.09 \mathrm{nmol} / \mathrm{L}$, 5a-dihydrotestosterone of $0.07 \mathrm{ng} / \mathrm{mL}$, LH of $16.8 \mathrm{mlU} / \mathrm{mL}, \mathrm{FSH}$ of $23.8 \mathrm{mlU} / \mathrm{mL}$, and E2 of $12.4 \mathrm{pg} / \mathrm{mL}$. These results indicated that the patient's hormone levels had

Table 1. Laboratory hormone and tumor markers of the patient

\begin{tabular}{|c|c|c|c|c|}
\hline \multirow{2}{*}{ Hormone or tumor marker } & \multicolumn{2}{|c|}{ Result } & \multirow{2}{*}{ Normal range } & \multirow{2}{*}{ Unit } \\
\hline & Preoperative & Postoperative $^{a)}$ & & \\
\hline FSH & 9.3 & 23.8 & $0.8-15.7$ & $\mathrm{mlU} / \mathrm{mL}$ \\
\hline LH & 5.2 & 16.8 & $1-20$ & $\mathrm{mlU} / \mathrm{mL}$ \\
\hline Prolactin & 8.2 & - & $3.8-31.4$ & $\mathrm{ng} / \mathrm{mL}$ \\
\hline Cortisol & 10.4 & - & $6.0-25.0$ & $\mathrm{mcg} / \mathrm{dL}$ \\
\hline Growth hormone & $<0.05$ & - & $0.1-8.0$ & $\mathrm{ng} / \mathrm{mL}$ \\
\hline E2 & 48.5 & 12.4 & $15-350$ & $\mathrm{pg} / \mathrm{mL}$ \\
\hline Testosterone (total) & 13.52 & $<0.09$ & $0.09-1.6$ & $\mathrm{nmol} / \mathrm{L}$ \\
\hline Sex hormone binding globulin & 30.4 & 34.3 & $6-152$ & $\mathrm{nmol} / \mathrm{L}$ \\
\hline Free testosterone index & 44.5 & 1.3 & $0.4-19.6$ & - \\
\hline IGF-1 (somatomedin-C) & 119 & - & $55-248$ & $\mathrm{ng} / \mathrm{mL}$ \\
\hline ACTH & 4.8 & - & $3.5-13.2$ & $\mathrm{pmol} / \mathrm{L}$ \\
\hline C-peptide-anteprandial & 4.52 & - & $0.6-2.3$ & $\mathrm{ng} / \mathrm{mL}$ \\
\hline C-peptide-postprandial & 10.46 & - & $0.6-2.3$ & $\mathrm{ng} / \mathrm{mL}$ \\
\hline Insulin-anteprandial & 29.9 & - & $1.0-10.7$ & $\mathrm{mclU} / \mathrm{mL}$ \\
\hline Insulin-postprandial & 122.4 & - & $1.0-10.7$ & $\mathrm{mclU} / \mathrm{mL}$ \\
\hline HbA1c (NGSP) & 6.4 & 6.0 & $4.8-6.3$ & $\%$ \\
\hline $\mathrm{HbA1c}(\mathrm{IFCC})$ & 46 & 42 & $29-45$ & $\mathrm{mmol} / \mathrm{mol}$ \\
\hline eAG & 137 & 126 & $91-134$ & $\mathrm{mg} / \mathrm{dL}$ \\
\hline DHEA-S & 71.8 & 76.5 & $35.0-430.0$ & $\mathrm{mcg} / \mathrm{dL}$ \\
\hline 17-hydroxyprogesterone & 2.05 & 0.93 & $0.11-5.00$ & $\mathrm{ng} / \mathrm{mL}$ \\
\hline 5a-dihydrotestosterone & 0.54 & 0.07 & $0.05-0.30$ & $\mathrm{ng} / \mathrm{mL}$ \\
\hline CA 19-9 & 8.9 & - & $0.8-24.0$ & $\mathrm{U} / \mathrm{mL}$ \\
\hline CA 125 & 14.7 & - & $0.6-35.0$ & $\mathrm{U} / \mathrm{mL}$ \\
\hline alpha-fetoprotein & 3.1 & - & $1.1-5.0$ & $\mathrm{ng} / \mathrm{mL}$ \\
\hline
\end{tabular}

FSH, follicle-stimulating hormone; LH, luteinizing hormone; E2, estradiol; IGF-1, insulin-like growth factor 1; ACTH, adrenocorticotropic hormone; NGSP, national glycohemoglobin standardization program; IFCC, International Federation of Clinical Chemistry; eAG, estimated average glucose; DHEA-S, dehydroepiandrosterone sulfate; CA, cancer antigen.

a)For values that were initially abnormal, follow-up was performed 3 weeks postoperatively. 


\section{Obstetrics \& Gynecology Science}

Jinkyoung Kong, et al. Sertoli-Leydig cell tumor with PET-CT

dropped to the regular range of perimenopausal females (Table 1). Clinical signs of virilization, including hirsutism and thickening of voice, were significantly resolved at 15-month follow-up.

\section{Discussion}

SLCT is a very rare type of sex-cord stromal tumor with an incidence rate of $<0.5 \%$ [1]. Histologically, the tumor can be described as either well differentiated, intermediately differentiated, and poorly differentiated, with each level of differentiation indicating its own respective prognoses [2]. SLCT is mostly confined to the ovaries, unilateral, form large masses, and presents most commonly in females in their third and fourth decades. Although SLCT often secretes androgen and androgen precursors, clinical manifestation of virilization occurs in only approximately $30 \%$ of patients [2].

In the current case, the patient displayed hirsutism, moonface, and central obesity, with no palpable abdominal and pelvic mass or pain. Furthermore, a fluticasone-containing inhaler had been used to manage asthma for 20 years, initially putting the patient under the suspicion for iatrogenic Cushing's syndrome. Hormonal tests revealed subnormal levels of testosterone; therefore, a series of imaging tests were performed to find androgen-secreting tumors. Excess androgen production may occur in diseases such as adrenal hyperplasia, adrenal gland tumors, ovarian hyperthecosis, sex-cord stromal tumors, and polycystic ovarian syndrome, although the profiles of androgen precursors may vary [3]. In majority of cases, SLCT measures 5-15 cm in diameter, and its diagnosis can be made via transvaginal sonography, abdominopelvic $\mathrm{CT}$, and pelvis MRI, which typically appear as solid and noncalcified lesions [4-6]. Transvaginal sonography with color Doppler may easily detect SLCT since the tumor is often well vascularized [5]. However, approximately $20 \%$ of SLCTs are small in size. Especially for the Leydig cell tumors, the average mass size is approximately $3 \mathrm{~cm}$; thus, it is not easily detected by conventional diagnostic imaging tests $[1,7]$. The present case involved a mass lesion of $1.5 \mathrm{~cm}$ that resulted in negative findings under conventional methods such as pelvic ultrasonography, abdominopelvic $\mathrm{CT}$, and pelvic MRI, whereas PET-CT displayed positive FDG uptake with precision. Another method for the diagnosis and localization of SLCT may be selective ovarian/adrenal venous catheterization and hormonal sampling. However, the procedure is invasive and has an accuracy rate of $66 \%$; therefore, SLCT may be considered when imaging studies cannot be performed or do not reveal any lesions $[1,8]$.

According to the previous literature, PET-CT with MRI or selective catheterization were used to detect androgenproducing ovarian tumors not found in ultrasonography and abdominopelvic CT $[9,10]$. These cases also demonstrate the potential diagnostic power of PET-CT in detecting SLCT. Nevertheless, this case differs from the previous reports in that the PET-CT was performed to precisely locate the tumor that was otherwise indistinctive on conventional diagnostic imaging tests. Therefore, the current case provides information on the usefulness of PET-CT in establishing preoperative diagnosis and localization for indiscrete SLCT. However, in premenopausal and perimenopausal females, there were previous cases where PET-CT showed false-positive results due to increased physiologic FDG uptake during ovulation and the presence of corpus luteal or functional ovarian cysts. Thus, the findings from PET-CT should be evaluated carefully $[11,12]$.

SLCT can be classified as benign or malignant according to the degree of differentiation, and its prognosis is correlated with the tumor's stage and differentiation [1]. Therefore, prompt detection and surgical removal of the tumor are pivotal in determining patient's prognosis. Total hysterectomy with bilateral salpingo-oophorectomy is recommended in patients with no future pregnancy plans. Otherwise, unilateral oophorectomy can be performed for those who wanted to preserve their fertility. If the tumor is detected under conventional imaging in conjunction with appropriate biochemical findings, then the physician has can easily establish the treatment plans. However, if the tumor proves cannot be easily located, as was in the case of this patient, setting the appropriate treatment strategies may be jeopardized, especially in patients desiring to preserve fertility. Hence, we propose that PET-CT may be a useful tool in detecting the suspected SLCT when other conventional methods have failed to localize the tumor. This adjunctive role of PET-CT is clinically important, as explorative surgery creates unwarranted risks and anxiety especially for female who wanted to preserve their fertility.

In addition, despite having a favorable prognosis with an overall 5-year survival rate of 70-90\%, SLCT has been found to cause either recurrence or metastasis in $18 \%$ of patients [2]. In general, periodic follow-up of hormone levels includ- 


\section{Obstetrics \& Gynecology Science}

Vol. 62, No. 3, 2019

ing testosterone and initially elevated tumor markers are recommended after the surgical removal of SLCT. Moreover, measurement of serum inhibin or calretinin levels may be helpful [13]. Therefore, PET-CT in conjunction with these tumor markers may have an additional value in detecting early tumor recurrence or distant metastasis especially for poorly differentiated tumors.

\section{Conflict of interest}

No potential conflict of interest relevant to this article was reported.

\section{Ethical approval}

The study was approved by the Institutional Review Board of Gangnam Severance Hospital (3-2012-0230) and performed in accordance with the principles of the Declaration of Helsinki. Written informed consents were obtained.

\section{Patient consent}

The patient provided written informed consent for the publication and the use of images under the restriction that no identifiable personal information is revealed in the process.

\section{References}

1. Gui T, Cao D, Shen $K$, Yang J, Zhang $Y$, Yu Q, et al. A clinicopathological analysis of 40 cases of ovarian Sertoli-Leydig cell tumors. Gynecol Oncol 2012;127:384-9.

2. Young RH, Scully RE. Ovarian Sertoli-Leydig cell tumors. A clinicopathological analysis of 207 cases. Am J Surg Pathol 1985;9:543-69.

3. Tekin O, Avci Z, Isik B, Ozkara A, Uraldi C, Catal F, et al. Hirsutism: common clinical problem or index of serious disease? MedGenMed 2004;6:56.
4. Brojeni NR, Salehian B. Androgen secreting ovarian tumors. MOJ Women's Health 2017;5:327-30.

5. Demidov VN, Lipatenkova J, Vikhareva O, Van Holsbeke C, Timmerman D, Valentin L. Imaging of gynecological disease (2): clinical and ultrasound characteristics of Sertoli cell tumors, Sertoli-Leydig cell tumors and Leydig cell tumors. Ultrasound Obstet Gynecol 2008;31:85-91.

6. Tsuzuki Y, Kikuchi I, Nojima M, Yoshida K, Hashizume A, Tomita S. A case report: ovarian Sertoli-Leydig cell tumor with hyperestrogenism and endometrial hyperplasia in a postmenopausal woman. Jpn Clin Med 2017;8:1179066017695239.

7. Baiocchi G, Manci N, Angeletti G, Celleno R, Fratini D, Gilardi $G$. Pure Leydig cell tumour (hilus cell) of the ovary: a rare cause of virilization after menopause. Gynecol Obstet Invest 1997:44:141-4.

8. Levens ED, Whitcomb BW, Csokmay JM, Nieman LK. Selective venous sampling for androgen-producing ovarian pathology. Clin Endocrinol (Oxf) 2009;70:606-14.

9. McCarthy-Keith DM, Hill M, Norian JM, Millo C, McKeeby J, Armstrong AY. Use of F 18-fluoro-D-glucosepositron emission tomography-computed tomography to localize a hilar cell tumor of the ovary. Fertil Steril 2010;94:753.e11-753.e14.

10. Matuszczyk A, Petersenn S, Lahner $H$, Haude M, Veit $P$, Becker JU, et al. Androgenproduzierender Leydig-zelltumor des ovars als ursache von hirsutismus bei einer postmenopausalen frau. Med Klin Intensivmed Notfmed 2007;102:259-62.

11. Short S, Hoskin P, Wong W. Ovulation and increased FDG uptake on PET: potential for a false-positive result. Clin Nucl Med 2005;30:707.

12. Ho KC, Ng KK, Yen TC, Chou HH. An ovary in luteal phase mimicking common iliac lymph node metastasis from a primary cutaneous peripheral primitive neuroectodermal tumour as revealed by 18-fluoro-2-deoxyglucose positron emission tomography. $\mathrm{Br} J$ Radiol 2005;78:343-5.

13. Zhang HY, Zhu JE, Huang W, Zhu J. Clinicopathologic features of ovarian Sertoli-Leydig cell tumors. Int J Clin Exp Pathol 2014;7:6956-64. 